\title{
Evaluation of Polymerase Chain Reaction and Cobas TaqMan Real Time PCR in the Diagnosis of Tuberculosis: Indian Prospective
}

\author{
Mradula Singh ${ }^{1}$, Paras Singh $^{1 *}$, Vithal Prasad Myneedu $^{2}$, Manpreet Bhalla ${ }^{2}$, Puncham Adlakha ${ }^{1}$, \\ Pusphendra Verma ${ }^{3}$, Rohit Sarin ${ }^{4}$ \\ ${ }^{1}$ Department of Molecular Medicine, National Institute of Tuberculosis and Respiratory Diseases, Sri Aurobindo Marg, \\ New Delhi-110030, India \\ ${ }^{2}$ Department of Microbiology, National Institute of Tuberculosis and Respiratory Diseases, Sri Aurobindo Marg, New Delhi-110030, India \\ ${ }^{3}$ Department of tuberculosis \& Respiratory Diseases, National Institute of Tuberculosis and Respiratory Diseases, Sri Aurobindo Marg, \\ New Delhi-110030, India \\ ${ }^{4}$ Director, National Institute of Tuberculosis and Respiratory Diseases, Sri Aurobindo Marg, New Delhi-110030, India \\ Corresponding Author: parasaiims@hotmail.com
}

Copyright @ 2013Horizon Research Publishing All rights reserved.

\begin{abstract}
Background \& Objectives: Globally, tuberculosis (TB) still remains a major public health problem. India is a high TB burden country contributing to 26 per cent of global TB burden. Pulmonary tuberculosis (PTB) cases are more common ( $90 \%$ of cases) while extra pulmonary tuberculosis (EPTB) constitutes around 10 to $20 \%$ of all tuberculosis cases in India. The diagnosis of the EPTB cases is difficult because of few bacilli and consequently is associated with low sensitivity of Zhiel-Neelson (ZN) smear and culture on $\mathrm{LJ}$ media. The present study evaluates the utility of PCR for the detection of M. tuberculosis in paucibacillary extra pulmonary and pulmonary tuberculosis samples. Methods: A total of 561 samples (553 EPTB \& 8 PTB cases) were collected from the extra pulmonary and pulmonary tuberculosis patients which were processed for ZN smear, culture on LJ media and conventional PCR using two gene targets (IS6110 and MPB64). Results: The PCR positivity of IS6110 and MPB64 gene targets was found to be $91.3 \%(\mathrm{~N}=63 / 69)$ and $89.9 \%(\mathrm{~N}=62 / 69)$ in majority of smear negative \& culture positive (as a gold standard) extra pulmonary cases, respectively. However the PCR positivity was observed $100 \%$ in smear positive, culture positive Line probe assay tested MDR PTB cases (true positive controls; N=34). Further the PCR specificity was determined $>95 \%$ (true negative healthy controls; $\mathrm{N}=26$ ). The positivity of M. tuberculosis by IS6110 \& MPB 64 gene targets was found to be range of $88 \%$ to $100 \%$ in various clinical paucibacillary extra pulmonary samples i.e. pleural fluid, ascitic fluid, lymph node, pus, CSF and others. Our data on 64 samples (non respiratory, $\mathrm{n}=63$ \& respiratory samples, $n=1$ ) revealed $40.6 \%$ positivity by Cobas TaqMan Real Time PCR (utilizing 16S rRNA probe; Roche, USA). Interpretation \& Conclusion: Our data revealed that utility

of both PCR and Real Time PCR in rapid diagnosis of $M$. tuberculosis in paucibacillary extra pulmonary tuberculosis samples in Indian scenario.

Keywords Culture, M.Tuberculosis, In-House PCR Assays, Extra Pulmonary Tuberculosis

\section{Introduction}

Tuberculosis (TB) remains a major global health problem, despite the availability of highly efficacious treatment for decades. India has the world's largest burden of tuberculosis (TB), accounting for one-fifth (21\%) of the global TB incidence. The global annual incidence estimate is 8.7 million, most of them children (especially in endemic areas), and it leads to approximately 1.4 million deaths annually [1].

Pulmonary (PTB) are more common (in about $90 \%$ of cases) [2] while extra pulmonary tuberculosis (EPTB) constitutes around 10 to $20 \%$ of all tuberculosis cases in India (which affects mainly the lymph nodes, meningitis, kidney, spine, and growing ends of the bones), with a 25 to $50 \%$ case mortality rate within months. The most common form of extra pulmonary tuberculosis (EPTB) is tuberculous pleural effusion \& lymphadenopathy. However, the disease in extra pulmonary tuberculosis cases most often remains undiagnosed and, even worse, untreated. Conventional methods like smear and culture on Lowenstein-Jenson (LJ) Media are of limited use in the diagnosis of extra pulmonary tuberculosis cases which is associated with low sensitivity because of few bacillary load, smear microscopy has both the problems of sensitivity and specificity [3 -5].
\end{abstract}


Several investigators reported $0.4-37 \%$ smear positivity \& $12-45 \%$ culture positivity in variable proportional in different biological samples [6-10].

For the rapid and accurate diagnosis of infectious diseases, polymerase chain reaction (PCR) technique \& TaqMan Real time PCR have attracted considerable interest because of high degree of sensitivity and specificity over the conventional methods, particularly with the hope of shortening the time required to detect and identify Mycobacterium tuberculosis in respiratory and non-respiratory samples. These molecular tools and methods can be used for the confirmation of identity of isolates, direct detection of gene sequences from the clinical specimen and also molecular detection of drug resistance [4, 11-13].

The role of PCR in the diagnosis of extra pulmonary tuberculosis cases has been evaluated extensively as an alternative diagnostic tool and has yielded variable results, with sensitivities ranging between 42 and $100 \%$ and specificities ranging between 85 and $100 \%$ using various PCR targets such as IS6110, MPB64 (MPt64), TRC4, GCRS, etc. However, due to variability in the sensitivity rates in different studies, the role of PCR remains controversial $[3,9$, 11, 14-16].

Highly conserved insertion sequences, IS6110, is most commonly used in the detection of $M$. tuberculosis. The range of IS6110 copies among isolates varied from 0-19 in the $M$. tuberculosis genome $[16,17]$. However, the sensitivity and specificity of IS6110 sequence in the diagnosis of tuberculosis remains uncertain, and needs to be include other various PCR targets reliable screening test for tuberculosis in clinical specimen such as devR, TRC4, GCRS, MPB64 (MPt64), etc. [5, 11, 14,15]. MPB64 is secretary protein, it has been implicated in the virulence and pathogenesis of M.tuberculosis [18]. These assays targeting various gene segments, have abbreviated the turn around time for definitive mycobacteriological detection in the laboratory to 1-2 days, besides being more sensitive than conventional methods. A prompt diagnosis is indispensable for initiating appropriate treatment. The Cobas Amplicor M.TUBERCULOSIS assay for direct detection of M.tuberculosis complex (M.TUBERCULOSISC) in pulmonary tuberculosis samples have been used in many studies [12, 19, 20, 21]. The Amplicor assay was approved by the FDA for testing on smear-positive respiratory samples. The Cobas Amplicor M.TUBERCULOSIS assay is based on amplification of a segment of the 16S rRNA gene, followed by colorimetric detection of the PCR product by probe hybridization. The present study evaluates the utility of PCR (IS6110 and MPB64 gene targets) \& TaqMan Real Time-PCR in the detection of M.tuberculosis in majority of smear negative paucibacillary extra pulmonary samples in Indian scenario.

\section{Material \& Methods}

\subsection{Study Subject}

From 2011 to 2013 year, we conducted this study in National Institute of Tuberculosis and Respiratory Diseases, New Delhi, India. Different categories of samples (sputum for pulmonary tuberculosis and body fluids for extra-pulmonary cases) were collected from all study population. Current study was approved by research \& ethics committee of National Institute of Tuberculosis and Respiratory Diseases in 2011.

\subsection{Laboratory Methods}

\subsubsection{Collection of the Clinical samples}

A total of 561 clinical samples [(423 male; age mean 38.5) and (138 female; age mean 31.2) of suspected tuberculosis cases were collected in sterile container from the outdoor and indoor Department of National Institute of Tuberculosis and Respiratory Diseases, Delhi for this pilot study during the period of 2011-2013 year. The clinical samples were from Delhi $(\mathrm{N}=157)$, Delhi NCR $(\mathrm{N}=322)$, Bihar $(\mathrm{N}=9)$, Haryana $(\mathrm{N}=25)$, Rajasthan $(\mathrm{N}=1)$, Uttar Pradesh $(\mathrm{N}=41)$, Uttaranchal $(\mathrm{N}=3)$, Tamilnadu $(\mathrm{N}=1)$ and West Bengal $(\mathrm{N}=2)$.

A total 561 clinical samples included, 416 pleural fluid, 31 pus, 47 ascitic fluid, 34 lymph node aspirate, 5 cerebrospinal fluid (CSF), 4 endometrial fluid, 6 peritoneal fluid, 6 sputum, 2 bronchial wash and 10 others were processed for the investigation of smear, culture on Lowenstein Jenson (LJ) media and for conventional \& Real Time PCR to detect M.tuberculosis identification in clinical samples (Figure 1). Majority of the samples were pleural fluid. A detailed clinical history, sex, and age were also collected from the requisition form that accompanied with samples.

On the other hand healthy controls $(\mathrm{N}=26)$ TB negative and TB positive (smear positive, culture positive Line probe assay tested in MDR PTB; N=34) were also recruited as negative and positive controls H37Rv, M.tuberculsois, respectively (Figure 2 and Figure 3).

Inclusion criteria: The inclusion criteria of the study was recruitment of tuberculosis samples which included pleural fluid, ascitic fluids, CSF, lymph nodes aspirates, pus, endometrial fluid, peritoneal fluid, sputum, bronchial wash and others samples) with required sufficient volume to process the paucibacillary samples.

Data of clinically presentations, radiological and other laboratory examinations for diagnosis of extra-pulmonary tuberculosis (included smears and culture and other cyto-pathological reports wherever available etc) were also collected from OPD and ward for these patients.

\subsubsection{Processing of the samples}

All 561 samples were decontaminated by standard protocol i.e. $\quad N$-acetyl-L-cysteine (NALC)-sodium hydroxide $(\mathrm{NaOH})$ procedure which included $2 \% \mathrm{NaOH}, 2.9 \%$ trisodium citrate, $0.5 \%$ NALC [22]. The processed samples were used for $\mathrm{ZN}$ smear, culture on $\mathrm{LJ}$ medium (bacteriological identification as a gold standard) and for 
DNA extraction from all body fluids as well as sputum by QIAamp DNA Mini Kit (Qiagen, Germany) and by Amplicor Respiratory samples Preparation Kit according to manufacturer's instructions and protocols (Roche, USA). Equal volume $(100 \mu \mathrm{l})$ of decontaminated samples was used in DNA extraction for conventional PCR and Real Time PCR method. Eluted DNA was stored at $-20^{\circ} \mathrm{C}$. To avoid contamination during DNA extraction and amplification, strict precautions were taken, including separate areas for DNA extraction, reagent preparation, amplification and product detection and regular meticulous cleaning of surface with $10 \%$ hypochlorite were also applied to maintain the standard molecular laboratory procedures.

\subsubsection{DNA Amplification for Mycobacterium tuberculosis Detection}

Amplification of bacterial DNA was performed by using In-House PCR (IS6110 and MPB64 gene targets) in extracted DNA of all clinical samples as per the below mentioned protocols.

\subsubsection{In-house PCR}

Total $25 \mu$ l of PCR reaction volume was containing $1 \mathrm{x}$

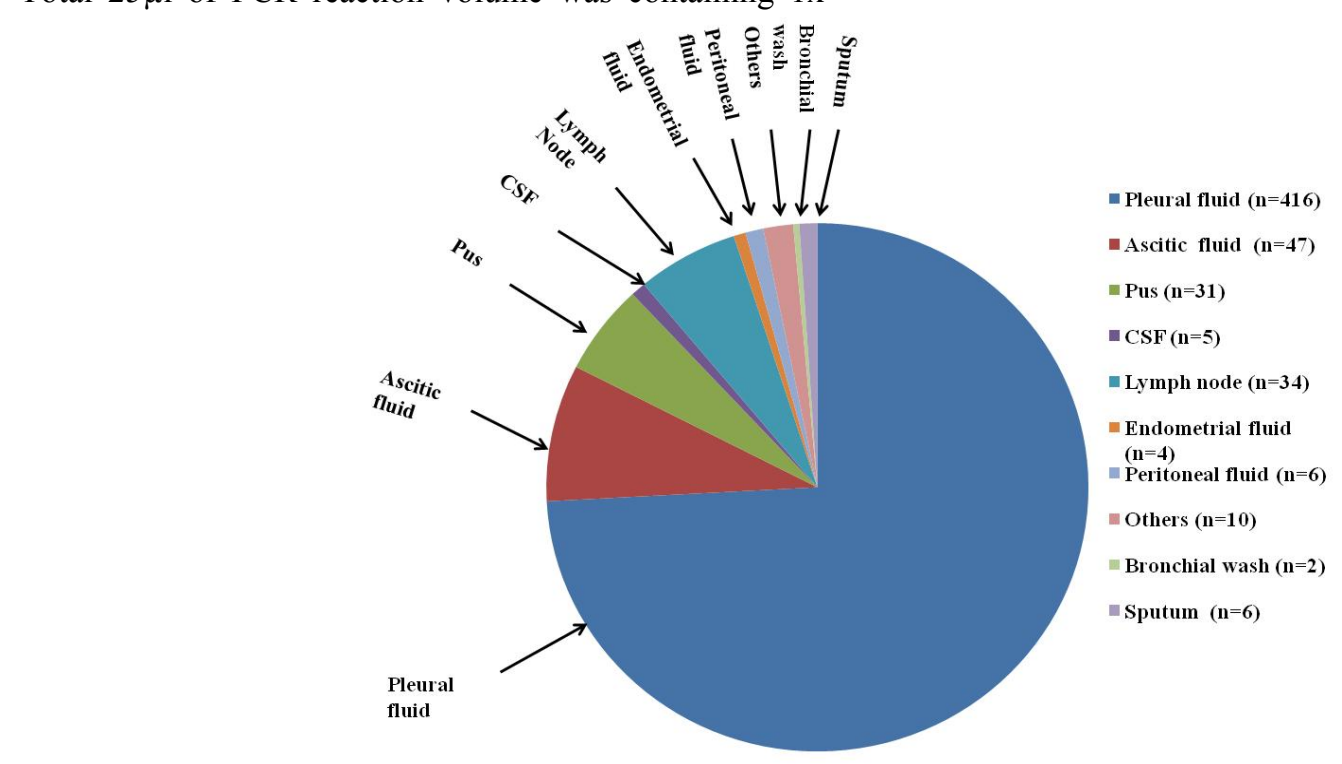

PCR buffer, $0.2 \mathrm{mM}$ dNTPs, 50ng of each primer (IS6110: Forward 5'- CCT GCG AGC GTA GGC GTC GG-3' and Reverse 5'-CTC GTC CAG CGC CGC TTC GG-3') \& MPB64: Forward 5'-TCC GCT GCC AGT CGT CTT CC-3' \& Reverse 5'-GTC CTC GCG AGT CTA GGC CA-3' [14, 23], 1 unit of Taq polymerase (Banglore Genei, India) and $10 \mu \mathrm{l}$ of tested sample DNA along with positive control (M.tuberculosis $\mathrm{H}_{37} \mathrm{Rv}$ ) and negative control lacking DNA (nuclease free water in place of template DNA).

The amplification was accomplished on a thermal cycler (9700 Applied Biosystem, thermal cycler, USA) with the following cycling parameters : $5 \mathrm{~min}$. at $94^{\circ} \mathrm{C}$ then one cycle of $30 \mathrm{sec}$ at $94{ }^{\circ} \mathrm{C}, 30 \mathrm{sec}$ at $68^{\circ} \mathrm{C}, 30 \mathrm{sec}$ for $72^{\circ} \mathrm{C}$, followed by 40 cycles, and a final extension of $10 \mathrm{~min}$. at $72^{\circ} \mathrm{C}$. The PCR products were resolved by $2 \%$ agarose gel electrophoresis for 60mins. The product size of IS6110 (123bp) \& MPB64 (240bp) were visualized on 2\% agarose gel electrophoresis for identification of these single gene targets amplicons (Figure 2, 3 and 4). DNA from PCR negative samples was spiked with M.tuberculsis DNA $\left(\mathrm{H}_{37} \mathrm{Rv}\right.$ strain) and reamplified to check for amplification inhibitors giving false negative results.

Figure 1. Graphical representation of clinical tuberculosis samples $(\mathrm{N}=561)$ recruited for the study during 2011-2013 period. Further extra pulmonary samples were categorized as pleural fluid $(\mathrm{N}=416)$, ascitic fluid $(\mathrm{N}=47)$, pus $(\mathrm{N}=31)$, Cerebrospinal fluid ( $\mathrm{CSF}, \mathrm{N}=5)$, lymph node $(\mathrm{N}=34)$, endometrial fluid $(\mathrm{N}=4)$, peritoneal fluid $(\mathrm{N}=6)$, others $(\mathrm{N}=10)$. PTB samples were sputum $(\mathrm{N}=6)$ and bronchial wash $(\mathrm{N}=2)$.

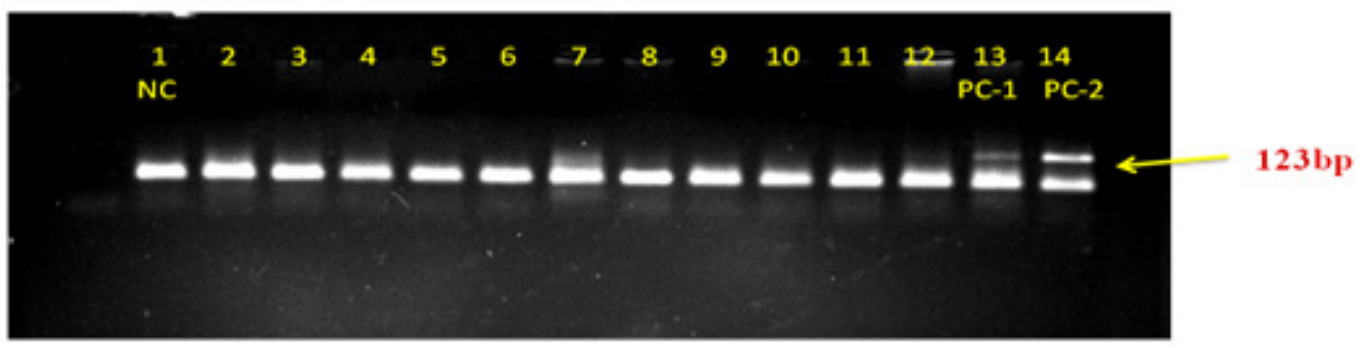

Figure 2. IS6110 gene targeted In-house PCR for detection of M. tuberculosis. Electrophoretic separation of the amplicon into $2 \%$ agarose gel is documented across Lanes 1-14. Lanes-1 represents the negative control (nuclease free water), Lane-2 to 12 represent clinical healthy control samples, Lanes-13 (PC-1 diluted), 14 (PC-2 concentrated) was positive control (M. tuberculosis culture H37Rv). The presence of a 123 bp amplicon in the lanes 13 and 14 indicated the presence of the target. 


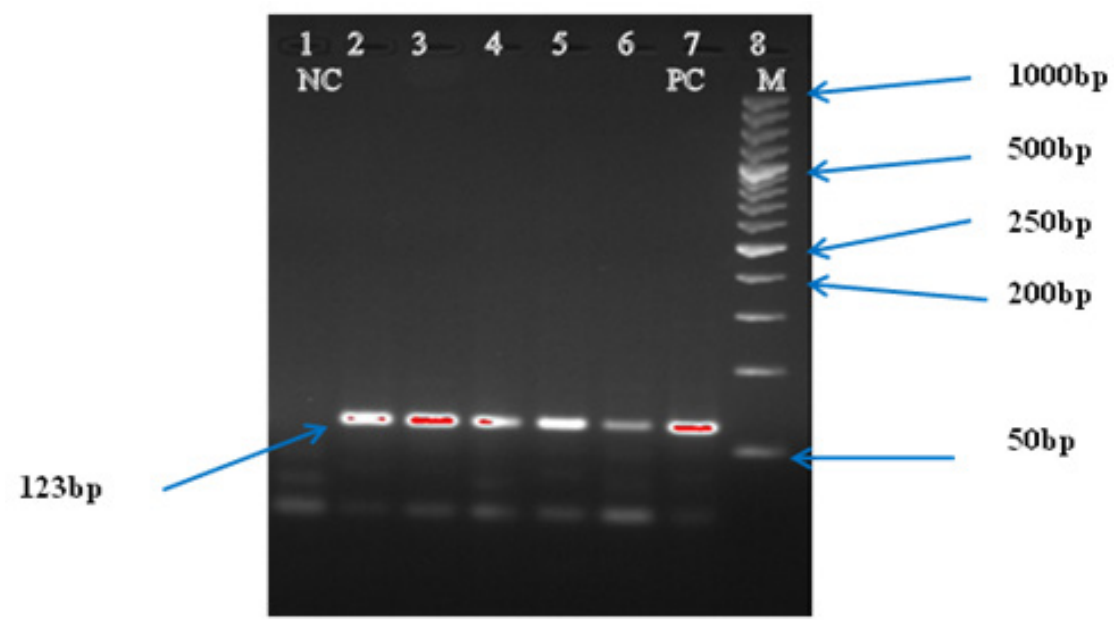

Figure 3. IS6110 PCR (123bp) in PTB cases. Lane 1- Negative control (NC), Lane 2 to 9- clinical sputum samples (smear positive, culture positive and LPA positive), Lane 10- positive control ( $\mathrm{PC}) \mathrm{H}_{37} \mathrm{Rv}$ M.tuberculosis and Lane 11- 100bp marker(M). Lane 2, 3 \& 4-10 indicated the presence of amplified gene target.

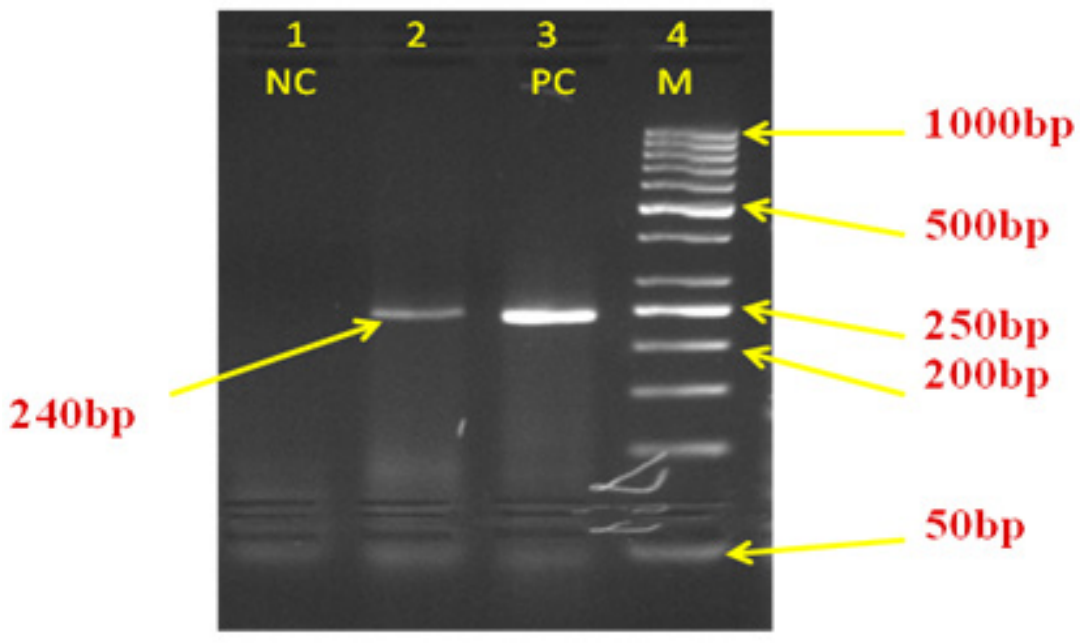

Figure 4. PCR targeted MPB 64 gene for the detection of M. tuberculosis. Electrophoresis separation of the amplicon into $2 \%$ agarose gel is documented across Lanes 1-4. Lane-1 represents the negative control (nuclease free water), Lane-2 represents clinical EPTB samples, Lane-4 was positive control (M. tuberculosis culture H37Rv). The presence of a $240 \mathrm{bp}$ amplicon in the lanes 2 and 3 indicated the presence of the target.

\subsubsection{Detection of M.tuberculosis by Real Time PCR}

Qualitative detection of Mycobacterium tuberculosis (M.TUBERCULOSIS) complex DNA were carried out using COBAS TaqMan M.TUBERCULOSIS Test (Roche Diagnostic Systems, USA) in suspected tuberculosis samples. This procedure targets 16S rRNA genes of mycobacterium genus and detects amplified products with specific probe and colorimetric assay. The Cobas taqMan M.TUBERCULOSIS test utilizes the TaqMan 48 analyzer for automated amplification and detection. The test includes two major steps: (i) preparation of DNA (ii) real time PCR. The assay permits the detection of amplified M.TUBERCULOSISC amplicon and internal control DNA, which is amplified and detected simultaneously with the samples. The internal control DNA (non-infectious plasmid DNA) was used to detect polymerase inhibitor that might be present in samples.
A total of 64 samples (2 smear positive, 7 culture positive and 55 smear negative and culture negative samples) were performed for Real Time PCR.

\subsection{DNA extraction}

The Amplicor Kit (having its own positive and negative controls for the test) was used for DNA extraction of the samples and controls i.e. MYCO (-) \& MYCO (+) using manufacturer's protocol.

Briefly, a $100 \mu l$ aliquot of the liquefied, decontaminated and concentrated respiratory and non-respiratory samples

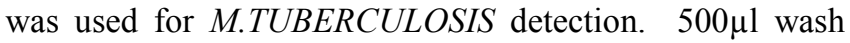
solution (RW) was added to each $100 \mu 1$ sample tube, vortexed \& centrifuged at $12,500 x \mathrm{~g}$ for 10 minutes. $100 \mu \mathrm{l}$ lysis reagent (RL) for each samples and $200 \mu 1 \mathrm{RL}$ for $50 \mu 1$ controls [MYCO (-) \& MYCO (+)] were added to the cell pellet, vortexed \& incubated at $60^{\circ} \mathrm{C} \pm 2^{\circ} \mathrm{C}$ for 45 minutes. 
$100 \mu \mathrm{l}$ neutralization reagent (RN) was added to each specimen and control tube. Samples were vortexes for 5 seconds at half speed and stored at $2-8^{\circ} \mathrm{C}$ before addition into working master mix.

\subsection{Amplification and detection}

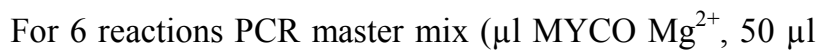
MYCO IC and $460 \mu \mathrm{l}$ M.TUBERCULOSIS MMX) was prepared according to manufacturer's protocol. $50 \mu \mathrm{l}$ template DNA of samples or controls were added into each K-tube containing 50 $\mu 1$ and loaded in Real Time PCR. The TaqMan 48 Analyzer determined the cycle threshold value $\left(\mathrm{C}_{\mathrm{T}}\right)$ for the DNA of M.TUBERCULOSISC and checked whether the $\mathrm{C}_{\mathrm{T}}$ values of the internal control DNA, the M.TUBERCULOSIS (+) Control, and the MYCO (-) Control were within the normal ranges. The M.TUBERCULOSIS (+) Control contains approximately 20 Copies/test of M.tuberculosis plasmid DNA sequence, for MYCO (-) Control the $\mathrm{Ct}$ values for M.TUBERCULOSIS DNA was above the limit for the assay or no $\mathrm{Ct}$ value for M.TUBERCULOSIS DNA was obtained, but valid $\mathrm{Ct}$ value was obtained for the Mycobacterium Internal Control DNA.

\section{Results}

The present study determined the significance of conventional and Real Time PCR for the early detection of M.tuberculosis in clinical samples in smear negative, culture positive paucibacillary tuberculosis cases. Out of 561 clinical suspected tuberculosis samples, 72 were found to be culture positive (data represented in Table-1) subjected to smear microscopy after ZN staining, culture on LJ media (as gold standard) to analyzed the mycobacterium growth and further conventional PCR (IS6110 and MPB64) and Real Time TaqMan PCR (16SrRNA).

Table 1. PCR positivity in culture positive (Gold standard) suspected TB samples

\begin{tabular}{|c|c|c|c|c|}
\hline \multicolumn{2}{|l|}{ Samples } & \multirow{2}{*}{ Smear } & \multicolumn{2}{|c|}{ Positive PCR for } \\
\hline Type & No. & & IS6110 N (\%) & MPB64 N (\%) \\
\hline \multirow{3}{*}{ Ascitic fluid } & \multirow{3}{*}{1} & Pos $(n=0)$ & & \\
\hline & & $\operatorname{Neg}(n=1)$ & $1(100)$ & $1(100)$ \\
\hline & & Total No. (\%) & $1(100)$ & $1(100)$ \\
\hline \multirow{3}{*}{ Lymph node } & \multirow{3}{*}{5} & Pos $(n=0)$ & & \\
\hline & & Neg $\quad(n=5)$ & $5(100)$ & $5(100)$ \\
\hline & & Total No. (\%) & $5(100)$ & $5(100)$ \\
\hline \multirow{3}{*}{ CSF } & \multirow{3}{*}{1} & Pos $\quad(n=0)$ & & \\
\hline & & Neg $\quad(n=1)$ & $1(100)$ & $1(100)$ \\
\hline & & Total No. (\%) & $1(100)$ & $1(100)$ \\
\hline \multirow{3}{*}{ Pleural Fluid } & \multirow{3}{*}{48} & Pos $\quad(n=7)$ & $7(100)$ & $7(100)$ \\
\hline & & $\operatorname{Neg}(n=41)$ & $36(87.8)$ & $35(85.4)$ \\
\hline & & Total No. (\%) & $43(89.6)$ & $42(87.5)$ \\
\hline \multirow{3}{*}{ Pus } & \multirow{3}{*}{9} & Pos $(n=0)$ & & \\
\hline & & $\operatorname{Neg}(n=9)$ & $8(88.9)$ & $8(88.9)$ \\
\hline & & Total No. (\%) & $8(88.9)$ & $8(88.9)$ \\
\hline \multirow{3}{*}{ Others } & \multirow{3}{*}{5} & Pos $(n=2)$ & $2(100)$ & $2(100)$ \\
\hline & & $\operatorname{Neg}(n=3)$ & $3(100)$ & $3(100)$ \\
\hline & & Total No. (\%) & $5(100)$ & $5(100)$ \\
\hline \multirow{3}{*}{ Total No. of EPTB } & \multirow{3}{*}{69} & $\operatorname{Pos}(n=9)$ & $9(100)$ & $9(100)$ \\
\hline & & $\operatorname{Neg}(n=60)$ & $54(90)$ & $53(88.3)$ \\
\hline & & Total No. (\%) & $63(91.3)$ & $62(89.9)$ \\
\hline \multirow{3}{*}{ Sputum } & \multirow{3}{*}{3} & Pos $(n=2)$ & $2(100)$ & $2(100)$ \\
\hline & & $\operatorname{Neg}(n=1)$ & 0 & 0 \\
\hline & & Total No. (\%) & $2(66.7)$ & $2(66.7)$ \\
\hline \multirow{3}{*}{ Total No. of PTB cases } & \multirow{3}{*}{3} & Pos $(n=2)$ & $2(100)$ & $2(100)$ \\
\hline & & $\operatorname{Neg}(n=1)$ & 0 & 0 \\
\hline & & Total No. (\%) & $2(66.7)$ & $2(66.7)$ \\
\hline Total EPTB + PTB cases $\quad(\%)$ & 72 & & $65(90.3)$ & $64(88.9)$ \\
\hline
\end{tabular}


Evaluation of Polymerase Chain Reaction and Cobas TaqMan Real Time PCR in the Diagnosis of Tuberculosis: Indian Prospective

Table 2. PCR positivity in culture negative suspected TB specimens

\begin{tabular}{|c|c|c|c|c|}
\hline \multicolumn{2}{|l|}{ Specimens } & \multirow{2}{*}{ Smear } & \multicolumn{2}{|c|}{ Positive PCR for } \\
\hline Type & No. & & IS6110 N (\%) & MPB 64(\%) \\
\hline \multirow{3}{*}{ Ascitic fluid } & \multirow{3}{*}{46} & $\operatorname{Pos}(\mathrm{n}=0)$ & - & - \\
\hline & & $\operatorname{Neg}(n=46)$ & $30(65.3)$ & $21(45.7)$ \\
\hline & & Total No. (\%) & $30(65.3)$ & $21(45.7)$ \\
\hline \multirow{3}{*}{ Lymph node } & \multirow{3}{*}{29} & $\operatorname{Pos}(n=2)$ & $2(100)$ & $1(50)$ \\
\hline & & Neg $\quad(n=27)$ & $21(77.8)$ & $16(59.3)$ \\
\hline & & Total No. (\%) & $23(79.3)$ & $17(58.6)$ \\
\hline \multirow{3}{*}{ CSF } & \multirow{3}{*}{4} & Pos $\quad(n=0)$ & - & - \\
\hline & & Neg $\quad(n=4)$ & $1(25)$ & $2(50)$ \\
\hline & & Total No. (\%) & $1(25)$ & $2(50)$ \\
\hline \multirow{3}{*}{ Endometrial Blood } & \multirow{3}{*}{4} & $\operatorname{Pos}(\mathrm{n}=0)$ & - & - \\
\hline & & $\operatorname{Neg}(n=4)$ & $3(75)$ & $3(75)$ \\
\hline & & Total No. (\%) & $3(75)$ & $3(75)$ \\
\hline \multirow{3}{*}{ Pleural Fluid } & \multirow{3}{*}{368} & Pos $\quad(n=6)$ & $5(83.3)$ & $5(83.3)$ \\
\hline & & $\operatorname{Neg}(n=362)$ & $210(58.1)$ & $204(56.4)$ \\
\hline & & Total No. (\%) & $215(58.4)$ & $209(56.8)$ \\
\hline \multirow{3}{*}{ Pus } & \multirow{3}{*}{22} & $\operatorname{Pos}(n=3)$ & $2(66.7)$ & $2(66.7)$ \\
\hline & & $\operatorname{Neg}(n=19)$ & $14(73.7)$ & $14(73.7)$ \\
\hline & & Total No. (\%) & $16(72.7)$ & $16(72.7)$ \\
\hline \multirow{3}{*}{ Peritoneal fluid } & \multirow{3}{*}{6} & $\operatorname{Pos}(n=0)$ & - & - \\
\hline & & $\operatorname{Neg}(n=6)$ & $4(66.7)$ & $2(33.3)$ \\
\hline & & Total No. (\%) & $4(66.7)$ & $2(33.3)$ \\
\hline \multirow{3}{*}{ Others (EPTB) } & \multirow{3}{*}{5} & $\operatorname{Pos}(\mathrm{n}=0)$ & - & - \\
\hline & & $\operatorname{Neg}(n=5)$ & $5(100)$ & $4(80)$ \\
\hline & & Total No. (\%) & $5(100)$ & $4(80)$ \\
\hline \multirow{3}{*}{ Total No. EPTB cases } & \multirow{3}{*}{484} & $\operatorname{Pos}(n=9 ; 1.9 \%)$ & $7(77.8)$ & $7(77.8)$ \\
\hline & & $\operatorname{Neg}(n=475 ; 98.1 \%)$ & $290(61.1)$ & $267(56.2)$ \\
\hline & & Total No. (\%) & $297(61.4)$ & $274(56.6)$ \\
\hline \multirow{3}{*}{ Sputum } & \multirow{3}{*}{3} & $\operatorname{Pos}(n=0)$ & - & - \\
\hline & & $\operatorname{Neg}(n=3)$ & $2(66.7)$ & $1(33.3)$ \\
\hline & & Total No. $(\%)$ & $2(66.7)$ & $1(33.3)$ \\
\hline \multirow{3}{*}{ Bronchial wash } & \multirow{3}{*}{2} & $\operatorname{Pos}(n=0)$ & - & - \\
\hline & & $\operatorname{Neg}(n=2)$ & $2(100)$ & $2(100)$ \\
\hline & & Total No. (\%) & $2(100)$ & $2(100)$ \\
\hline \multirow{3}{*}{ Total No. PTB } & \multirow{3}{*}{5} & $\operatorname{Pos}(n=0)$ & - & - \\
\hline & & $\operatorname{Neg}(n=5)$ & $4(80)$ & $3(60)$ \\
\hline & & Total No. $(\%)$ & $4(80)$ & $3(60)$ \\
\hline Total PTB + EPTB cases $(\%)$ & 489 & & $301(61.6)$ & 277 (56.6) \\
\hline
\end{tabular}


Table 3. Comparative results of Cobas TaqMan Real Time PCR (16SrRNA gene) in TB samples

\begin{tabular}{|c|c|c|c|c|c|}
\hline Smear/ culture (N, \%) & $\begin{array}{c}\text { smear +ve, } \\
\text { culture +ve } \\
(\mathrm{a}=0 / 64 ; 0 \%)\end{array}$ & $\begin{array}{c}\text { smear +ve, } \\
\text { culture -ve } \\
(\mathrm{b}=2 / 64 ; 3.1 \%)\end{array}$ & $\begin{array}{c}\text { smear }-\mathrm{ve}, \\
\text { culture }+\mathrm{ve} \\
(\mathrm{c}=7 / 64 ; 10.9 \%)\end{array}$ & $\begin{array}{c}\text { smear -ve, } \\
\text { culture -ve } \\
(\mathrm{d}=55 / 64 ; 85.9 \%)\end{array}$ & $\begin{array}{c}\text { Total PCR } \\
\text { positive } \\
(\mathrm{N}=64)\end{array}$ \\
\hline IS6110 PCR (\%) & - & $2(100)$ & $7(100)$ & $35(63.6)$ & $44(68.7)$ \\
\hline MPB 64 PCR (\%) & - & $1(100)$ & $7(100)$ & $32(58.2)$ & $40(62.5)$ \\
\hline $\begin{array}{c}\text { Real Time PCR } \\
(16 \text { SrRNA; \%) }\end{array}$ & - & $2(100)$ & $7(71.4)$ & $42(34.5)$ & $26(40.6)$ \\
\hline $\begin{array}{c}\text { Over all PCR positive } \\
\text { (PCR \& RT-PCR) } \\
(\mathrm{N}=64)\end{array}$ & - & $2(100)$ & $7(100)$ & $46.4)$ & $51(79.7)$ \\
\hline
\end{tabular}

PTB cases: $\mathrm{N}=1 ; \quad$ EPTB cases: $\mathrm{N}=63 ; \quad$ Total $\mathrm{No}=64$

Total Smear positives: $\mathrm{n}=2(3.1 \%)$

Total Culture positives: $\mathrm{n}=7(10.9 \%)$

Total Smear and Culture positives: $\mathrm{n}=9(14.1 \%)$

\subsection{In-House Pcr Results}

This study showed that the PCR positivity of IS6110 and MPB64 gene targets was found to be $91.3 \%(63 / 69)$ and $89.9 \%(62 / 69)$ in majority of smear negative \& culture positive (as a gold standard) paucibacillary extra pulmonary cases, respectively. However the PCR positivity was observed $100 \%$ in smear positive, culture positive Line probe assay tested in MDR PTB cases (true positive controls; N=34 Figure 3). Further the PCR specificity was determined $>95 \%$ (true negative healthy controls or non-TB subjects; $\mathrm{N}=26$; Figure 2 ). The $\mathrm{PCR}$ positivity of M. tuberculosis by IS6110 \& MPB 64 gene targets was found to be $88 \%$ to $100 \%$ in various clinical samples paucibacillary smear negative extra pulmonary samples i.e. pleural fluid (88\%), ascitic fluid (100\%), lymph node (100\%), pus (89\%), CSF $(100 \%)$ and others $(100 \%$; Table-1). On the other hand, our data in culture negative TB samples revealed $61.4 \%$ and $56.6 \%$ PCR positivity for IS6110 and MPB 64 gene targets, respectively (Table: 2)

\subsection{Real Time PCR Results}

Simultaneously, with conventional PCR (IS6110 and MPB64), only 64 samples were performed for COBAS TaqMan M.TUBERCULOSIS test Kit by Real Time PCR. Out of 64 samples, $68.7 \%(44 / 64)$ and $62.5 \%(40 / 64)$ samples were positive with both conventional PCR methods (IS6110 and MPB64, respectively) whereas M.tuberculosis was detected only in $40.6 \%(26 / 64)$ cases by TaqMan Real Time PCR technique. The over all PCR positivity (conventional and RT-PCR) was increased up to $79.7 \%$ (51/64; Table 3) to detect M.tuberculosis in tuberculosis samples.

\section{Discussion}

The major challenge in the diagnosis of extra pulmonary tuberculosis is detection of M.tuberculosis. Conventional methods including smear and culture have poor sensitivity due to the paucibacillary load in the samples. Without an affirmative answers, clinicians could not start treatment due to the delayed diagnosis. Therefore, a high index of suspicion is necessary to make an early diagnosis, and quite often, more than one procedure is necessary for the confirmation of the diagnosis. With the development of novel \& rapid molecular techniques, this delay in the accurate diagnosis of the disease is minimized but till date it could not replace traditional techniques in contrast to diagnostic modalities for other pathogens, like Chlamydia or Mycoplasma[5,7,9,10,12,24,25]. In order to identify tuberculosis in patients of suspected extra pulmonary tuberculosis for the detection of M. tuberculosis in clinical samples, two well established gene targets for conventional PCR (IS6110 \& MPB64) were used. Current study showed the different PCR positive rates in various categories of body fluids. The PCR positivity of M. tuberculosis by IS6110 \& MPB 64 gene targets was found to be $88 \%$ to $100 \%$ in various clinical samples paucibacillary smear negative extra pulmonary samples i.e. pleural fluid (88\%), ascitic fluid $(100 \%)$, lymph node $(100 \%)$, pus $(89 \%)$, CSF $(100 \%)$ and others $(100 \%)$. Our data revealed the significance importance of M.tuberculosis PCR by utilizing two gene targets in the diagnosis of paucibacillary smear negative cases in Indian scenario.

Extra pulmonary TB is a significant health problem $(10-20 \%)$ in both developing and developed countries. The reported prevalence of extra pulmonary tuberculosis in India varies between $8.3 \%$ and $13.1 \%$ in different districts according to cohort analysis [3].

Several studies reported low detection rate by smear in extra pulmonary tuberculosis cases are less than $10 \%$ in pleural fluid [6]; $0.4 \%$ [26] in endometrial samples, $13 \%$ in lymph node, skin and other body fluids [19], 5.4\% in peritoneal fluids, CSF, cervical lymph node biopsies, tissue biopsy and pericardial fluid [10], zero percentage in endometrial biopsy, gastric aspirate and pus [9] whereas culture positivity was $4 \%$ in peritoneal fluids, CSF, cervical lymph node biopsies, tissue biopsy and pericardial fluid [10]; $43.3 \%$ in lymph node, skin, other body fluids \& 
sputum [19], 12 to $70 \%$ in pleural fluid [6] and $4.3 \%$ in endometrial biopsy, gastric aspirate and pus [9]. In contrast to above reported studies, the current study showed a significant utility of PCR and Real time PCR in smear negative, paucibacillary respiratory \& non respiratory TB samples.

Various sensitivity of PCR using IS6110 has been reported in extra pulmonary samples i.e. $74.1 \%$ in tissue [27], $83 \%$ in pleural fluid, pleural tissue, and lymph node [15], $69.1 \%$ and $87.5 \%$ in lymph node $[5,12], 75 \%$ in clinical samples [7], 40\% in EPTB [9]. Chakarvorty et al [15] reported that IS6110 PCR efficiency was $90.9 \%$ for pleural tissue and $85.5 \%$ for pleural fluid and $68.4 \%$ lymph node samples. But in our findings by IS6110 \& MPB64, positivity was increased in pleural fluid (89\%) and lymph node $(100 \%)$ smear negative \& culture positive samples. These results further emphasized the significance of molecular diagnostic method for earlier diagnosis.

It has been reported that the sensitivity of PCR can be increased by using one more sets of primers in EPTB cases i.e. 77\% [5]. Similarly in our study, positivity of the PCR to detect M.tuberculosis was also increased (i.e. combined results of conventional and real time PCR in 64 tuberculosis samples) $79.7 \%$ (51/64). M.tuberculosis detection rate by single PCR was low i.e. $68.7 \%$ for IS6110, $62.5 \%$ for MPB64 PCR and $40.6 \%$ by Real time PCR. The low positivity rate through Amplicor Real time Roche assay in smear negative extra-pulmonary tuberculosis samples in our study revealed its more significance in smear-positive respiratory samples compared to smear negative paucibacillary extrapulmonary cases. It has been reported earlier that the Amplicor Real time assay has high sensitivity rate to detect M.tuberculosis in smear-positive respiratory samples [20].

Boukaline et al.19 reported the testing of EPTB cases by Real Time PCR method for M.tuberculosis diagnosis and analyzed the $53.8 \%$ sensitivity. Rimek et al.12 reported $87.5 \%$ \& $45.5 \%$ sensitivity, $100.0 \%$ \& $91.3 \%$ specificity of In-house PCR and the COBAS M.tuberculosis assays, respectively. This pilot study suggested the significance of the molecular tools in different body fluids of the suspected EPTB cases, compared to conventional method like smear (3.1\%) and culture (10.9\%).

\section{Conclusion}

This study reveals rapid molecular test such as PCR with more than one gene targets \& Real Time PCR methods have significant role for the early diagnosis (by decreasing time duration) of extra pulmonary tuberculosis cases, which is not diagnosed by conventional test (smear $\&$ culture). Further study needs to include more gene targets and to develop multiplex PCR assays for rapid diagnosis of M.tuberculosis in developing countries like India.

\section{Acknowledgements}

The study was funded by LRS Institute of Tuberculosis $\&$ Respiratory Diseases. We thank the staff members of the Department of Microbiology. We appreciate the participants for their good will to give the necessary information.

\section{REFERENCES}

[1] World Health Organization. "The global tuberculosis report 2012".

http://www.who.int/tb/publications/global_report/en/index.ht $\mathrm{ml} .2012$.

[2] S. D. Lawn, A. I. Zumla. "Tuberculosis". Lancet, 378, 57-72, 2011.

[3] A. K. Maurya, S. Kant, V. I. Nag, R. Kushwaha, T. N. Dhole. Detection of $123 \mathrm{bp}$ fragment of insertion element IS6110 Mycobacterium tuberculosis for diagnosis of extra pulmonary tuberculosis. Ind J Med Microbiol, 30, 182-186, 2012.

[4] R. Khosla, A. Dwivedi, B. C. Sarin, Sehajpal. Peripheral blood based C-PCR assay for diagnosing extra pulmonary tuberculosis. Ind J Exper Biol, 47, 447-453, 2009.

[5] H. B. Singh, P. Singh, G. P. S. Jadaun, K. Srivastava, V. D. Sharma, D. S. Chauhan, S. K. Sharma, V. M. Katoch. Simultaneous use of two PCR systems targeting IS6110 and MPB64 for confirmation of diagnosis of tuberculous lymphadenitis. J Commun Dis, 38, 274-279, 2006.

[6] A.N. Agarwal, D. Gupta, S. K. Jindal. Diagnosis of tubercular pleural effusion. Ind J Chest Dis Allied Sci, 41, 89-100, 1999.

[7] O. A. T. Alli, O. D. Ogbolu, O. O. Alaka. Direct molecular detection of Mycobacterium tuberculosis complex from clinical samples - An adjunct to cultural method of laboratory diagnosis of tuberculosis. North American J Med Sci, 3, 281 $-288,2011$.

[8] A. Jain. Extra pulmonary tuberculosis: A diagnostic dilemma. Ind J Clin Biochem, 26, 269-273, 2011.

[9] I. Shukla, S. Varshney, Sarfraz, A. Malik, Z. Ahmad. Evaluation of nested PCR targeting IS6110 of Mycobacterium tuberculosis for the diagnosis of pulmonary and extra-pulmonary tuberculosis. Biology and Medicine, 3, $171-175,2011$

[10] K. L. Therese, U. Jayanthi, H. N. Madhavan. Application of nested polymerase chain reaction (nPCR) using MPB64 gene primers to detect Mycobacterium tuberculosis DNA in clinical samples from extra pulmonary tuberculosis patients. Ind J Med Res, 122, 165-170, 2005.

[11] V. M. Katoch. Newer diagnostic techniques for tuberculosis. Ind J Med Res, 120, 418-428, 2004.

[12] D. Rimek, S. Tyagi, R. Kappe. Performance of an IS6110-based PCR assay and the COBAS amplicor M.TUBERCULOSIS PCR system for detection of Mycobacterium tuberculosis complex DNAin human lymph node samples. J Clin Microbiol, 40, 3089-3092, 2002. 
[13] K. K. Singh, M. D. Nair, K. Radhakrishnan, J. S. Tyagi. Utility of PCR assay in diagnosis of En-Plaque tuberculoma of the brain. J Clin Microbiol, 37, 467-470, 1999.

[14] N. V. Bhanu, U. B. Singh, M. Chakravorty, N. Suresh, J. Arora, T. Rana, D. Takkar, P. Seth. Improved diagnostic value of PCR in the diagnosis of female genital tuberculosis leading to infertility. J Med Microbiol, 54, 927-931, 2005.

[15] S. Chakravorty, M. K. Sen, J. S. Tyagi. Diagnosis of extra pulmonary tuberculosis by smear, culture, and PCR using universal sample processing technology. J Clin Microbiol, 43, 4357-4362, 2005.

[16] S. Sankar, S. Kuppanan, B. Balakrishnan, B. Nandagopal. Analysis of sequence diversity among IS6110 sequence of Mycobacterium tuberculosis: possible implications for PCR based detection. Bioinformation, 6, 283-5, 2011.

[17] D. S. Chauhan, V. D. Sharma, D. Parashar, A. Chauhan, D. Singh, H. B. Singh, R. Das, B.M. Aggarwal, B. Malhotra, A. Jain, M. Sharma, V.K. Kataria, J.K. Aggarwal, M.Hanif, A.Shahani, V.M. Katoch. Molecular typing of Mycobacterium tuberculosis isolates from different parts of India based on IS6110 element polymorphism using RFLP analysis. Ind J Med Res, 125, 577-581, 2007.

[18] L. Chen, X. He, X. Zhao, J. Su. Interaction of Mycobacterium tuberculosis MPB64 protein with heat shock protein 40. African J Microbiol Res,5, 394-398, 2011.

[19] S. H. Bouakline, J. P. Vincensini, V.Giacuzzo, P. H. Lagrange, J. L. Herrmann. Rapid diagnosis of extra pulmonary tuberculosis by PCR: Impact of sample preparation and DNA extraction. J Clin Microbiol, 41, 2323-2329, 2003.
[20] Y. C. Yang, P. L. Lu, S. C. Huang, Y. S. Jenh, R. Jou, T. C. Chang. Evaluation of the Cobas TaqMan M.TUBERCULOSIS test for direct detection of Mycobacterium tuberculosis complex in respiratory specimens. J Clin Microbiol, 49, 797-801, 2011.

[21] J. H. Chang, S. W. Kim, S. J. Lee, J. H. Lee, Y. J. Ryu. Clinical accuracy of Real Time PCR for the diagnosis of pulmonary tuberculosis. Chest Infect, 142, 203A.doi:10.1378/chest.139472, 2012.

[22] P. T. Kent, G. P. Kubica. Public Health Mycobacteriology: A guide for the level III laboratory. Washington, DC: U.S. Department of Health and Human Services, 1985.

[23] S. K. Sharma, A. Mohan. Tuberculosis: From an incurable scourge to a curable disease - journey over a millennium. Ind J Med Res, 137, 455-493, 2013.

[24] A. Ani, S. Okpe, M. Akambi, E. Ejelionu, B. Yakubu, O. Owolodun, P. Ekeh, A. Oche, D. Tyem, J. Idoko. Comparison of a DNA based PCR method with conventional methods for the detection of M. tuberculosis in Jos, Nigeria. J Infect Dev Ctries, 3, 470-475, 2009.

[25] A. Mashta, P. Mishra, S. Philipose, S. Tamilzhalagan, H. Mahmud, S. Bhaskar, P. Upadhyay. Diagnosis of tuberculosis: the experience at a specialized diagnostic laboratory J Negat Results Biomed, 10, 16-22, 2011.

[26] J. Agarwal, J. K. Gupta. Female genital tuberculosis - a retrospective clinicopathological study of 501 cases. Ind J Pathol Microbiol, 36, 389-397, 1993.

[27] K. Chawla, S. Gupta, C. Mukhopadhyay, P. S. Rao, S. S. Bhat. PCR for $M$. tuberculosis in tissue samples. J Infect Developing Countries, 3, 83-87, 2009. 